\title{
UNIVERSITY FUNDING FORMULAS: AN ANALYSIS OF THE QUEEBEC REFORMS AND INCENTIVES
}

\author{
PIER-ANDRÉ BOUCHARD ST-AMANT \\ ÉCOLE NATIONALE \\ D'ADMINISTRATION PUBLLIQUE
}

\author{
ALEXIS-NICOLAS BRABANT \\ ÉCOLE NATIONALE \\ D'ADMINISTRATION PUBLLIQUE
}

\author{
ÉRIC GERMAIN \\ HEC MONTRÉAL
}

\begin{abstract}
This paper analyzes the incentives induced by a formula to fund universities based primarily on enrolment. Using a simple game theoretical framework, we argue that the strategic behaviour induced by those formulas is to favour enrollment. We further argue that if the funding value differs by enrolment type, it introduces incentives to substitute enrolment where most profitable. If the public appropriations do not follow the outcomes induced by the formula, the incentives introduce a dynamic inconsistency, and funding per student can decline. We use these results to discuss the 2018 funding formula changes in Québec. We argue that Québec's latest reform should reduce substitution effects and increase graduate enrolment. We provide simulations of the reform's redistributive effects and show that some universities gain structural advantages over others. Whilst the reform, on a short-term basis, deploys a mechanism to mitigate these advantages, on a long-term basis the effect introduces a larger gap between Québec higher-education institutions.
\end{abstract}

Keywords: university funding, reforms, simulation, induced effects, post-secondary education, game theory

\section{Résumé}

Nous analysons les incitatifs induits par une formule de financement des universités qui est basée principalement sur l'effectif équivalent temps plein. Nous employons la théorie des jeux et argumentons que les comportements stratégiques induits par la formule augmentent les inscriptions. Nous argumentons également que s'il existe plusieurs familles de financement, financées à différentes valeurs, il y aura alors des incitatifs à substituer les inscriptions vers des familles plus profitables. Lorsque les crédits budgétaires ne suivent pas les comportements induits par la formule, une inconsistance dynamique apparaît, entraînant une réduction du financement par étudiant. Ces résultats sont discutés à la lumière de la réforme québécoise de la formule de financement des universités de 2018. Cette réforme devrait réduire les effets de substitution entre les programmes et induire une augmentation des inscriptions dans les programmes de deuxième et troisième cycles. Nous simulons également comment la nouvelle formule redistribue les fonds entre les universités et montrons comment certaines ont des avantages structurels. Bien que des mécanismes transitoires atténuent ces effets à court terme, nous montrons leur effet permanent à long terme.

Mots-clés : financement des universités, réformes, simulation, éducation supérieure, théorie des jeux

\section{Introduction}

Post-secondary education (PSE) is publicly funded in most industrialised countries. According to the Organisation for Economic Co-operation and Development's dataset (2017), member countries fund on average 69\% of their higher-level academic institutions. For instance, Canadian public funding averages $49 \%$ whilst the United States, with more private institutions, averages $35 \%$. Since public universities are largely subsidised, the rules and procedures used by public authorities to transfer the funds are crucial. These rules and procedures are often called a University Funding Formula. The effects these formulas cause in institutions (Umbricht, Fernandez, \& Ortagus, 2017) are important. If a formula is primarily based on enroled students, universities may change their behaviours to increase the total number of enroled students. In a general sense, a funding formula can alter certain behaviours, increase output with limited resources, 
and can be used to improve higher education through better access and efficiency (Jongbloed, 2010).

This paper focuses on the effects of enrolment-based funding formulas where the total funding is dynamically inconsistent. We say that the funding is dynamically inconsistent when there is a difference between the public appropriations determined by the budgetary process and the amount that would maintain the public funding per student constant, in real terms, as determined by the formula. ${ }^{1}$ We detailed this further in the subsection titled $A$ typology of enrollment-based formulas.

We use the core structure of the formula that is in place in several jurisdictions such as California, Texas, Québec or Ontario (CD Howe Institute, 2006; CEO Student-Centered Funding Formula Taskforce, 2018; MGT America, 2011). Using a game theoretical framework, we explore the strategic behaviours between universities when they seek to increase funding. First, we characterize under which circumstances a university that does not adopt an enrolment-growth strategy incurs losses. Second, for situations where enrolment does not have the same net value across programs, we show when the formula can generate incentives to substitute (shift) enrolment. We use these findings to study the changes to the 2018 university funding formula in Québec. We conclude that the reform reduces incentives for substitution and increases incentives to recruit graduate students.

We analyze further the consequences of the Québec 2018 reform and show how its implementation redistributes funds between universities. Using numerical simulations, we show how each component of the new formula would have affected universities if the rule had applied in past years. In particular, some measures of the reform are temporary, justified by the government to ease the transition from the old to the new formula. Such measures delay the long-term, structural impacts of the reform. By simulating the funding without the short-term measures, we show that the formula creates important redistributive effects for some institutions.

Our first section reviews empirical and theoretical papers on university funding formulas. We then present our methodology, and show the fundamental structure of a funding formula based on enrolment as well as our main theoretical results. We then portray the core of the Québec funding formula and its most recent reform. Finally, we present our simulations and comments on the specifics of the Québec reform.

\section{Literature Review}

Funding formulas clarify how funds are apportioned to each institution. These formulas reduce arbitrariness (Khinda, 2014) but may also introduce undesired effects (Geuna, 2001). Layzell (2007) describes four essential types of funding formulas: unconditional funding formulas (often dubbed historical funding) input-based funding formulas (such as enrolment-based), output-based funding formulas (such as graduate-based), and performance-based funding (PBF) formulas. Most jurisdictions use a combination of these formulas (Frølich, Schmidt, \& Rosa, 2010; MGT America, 2011; Miller, 2016), but often one component dominates (McKeown \& Layzell, 1994). This paper focuses on enrolment-based formulas.

Input-based formulas tie funding to observable inputs, such as the number of enroled students or hired professors, or the building size. The enrolment-based approach prevails in Québec, in states with large public systems in the United States and, currently, in Ontario (CEO, 2018; HEQCO, 2015; Québec government, 2018c). These input-based formulas are often weighted by program and tier. Output-based formulas tie the allocation of public funding to observable outputs, such as the research produced, graduation rates, adequacy of meeting market needs, and student access and diversity (Miller, 2016). As Miller points out, since funding formulas are enrolment-based they provide disincentives for timely student completion. The shift towards PBF aimed to make universities adopt strategies to help students graduate (Hillman, 2016). However, Hillman argues that because public organizations are complex, outcome-based evaluation would often fail to account for the complexity of a non-routinized organisation. To our knowledge, only Norway uses a "pure" approach with its taximeter formula (Frølich, 2006). PBFs are tied to achieving certain goals, such as deficit reduction or certain levels of graduation rates. Unlike with output-based formulas, the funding does not necessarily increase if the result achieved is better than the desired goal.

Del Rey (2001) was a pioneer in the study of game theory with respect to funding formulas. She modelled how universities are funded and analyzed how universities respond to formula changes. She showed that changing the weights (indicators of value) of each formula component changes universities' strategies. When the funding formula gives more weight to unconditional transfers, universities adopt a research strategy, and vice 
versa when less weight is given to unconditional transfers. Her model predicts that universities will concentrate resources in the production area most rewarded by the formula given the strategies used by other universities.

De Fraja and loassa (2002) have also studied the game theoretic interactions of funding formulas amongst competing universities. In De Fraja and Ioassa's setup, universities seek to increase prestige, which is what they find the most rewarding, achieved through research production and student recruitment. The authors shed light on how funds are allocated between research and teaching activities, depending on universities' incentives. The predicted outcome (i.e., Nash equilibrium—a combination of strategies such that no player can improve its payoff by changing its strategy given what other players do) leads universities to specialization. A subset of institutions would specialize in research, leaving the production of teaching to competing institutions.

Descriptive studies on the effects induced by formula changes are numerous (see McPherson and Schapiro, 2016). Since the early 1990s, the United States, the United Kingdom, Australia and Canada have experienced several variations in their funding formulas (Carpentier, 2018; Jones, 2004; Meek, 1991). Most states in the early 1990s adopted a PBF model (CEO Student-Centered Funding Formula Taskforce, 2018; Dougherty and Reddy, 2011; Hearn, 2015; Moore \& Russ-Eft, 2016). Lahr et al. (2004) interviewed university administrators, rectors, professors, and the university community in general, to evaluate the potential effects of such a policy (where, in some places, the increased proportion of PBF shifted from $2 \%$ to $85 \%$ ). They make two important observations: (a) a funding formula based solely on inputs (such as fulltime enroled students) produces few, if any, incentives to increase quality teaching or push graduation (Miller, 2016); (b) a formula that gives a higher weight to graduation provides incentives to restrain admissions (reducing accessibility). Some also suggest that PBF incentivizes universities to keep the same admission rate while reducing academic standards (Dougherty \& Reddy, 2011).

Some empirical studies quantify how funding formulas change universities' practices. Umbricht, Fernandez and Ortagus (2017) also use the difference in difference methodology to evaluate the effects of the change from enrolment-based to performance-based in Indiana. They also suggest that the change led to an important reduction in registration rates (from $80 \%$ to $68 \%$ in 2012). While this is empirical evidence that the policy change had some effects, it is not possible to infer whether the observed changes are the consequence of abandoning the first formula or introducing the second (or both). Disentangling these effects remains an open research issue.

\section{Methodology}

In analyzing incentives, we use a game-theoretical approach, whilst in our simulations, we use the observed enrolment dataset to simulate the 2018 changes to the Québec university formula.

\section{Game Theory}

Game theory is a framework for predicting the observed outcome of a system (a "game") where "players" can choose their strategies based on "rewards" (payoffs). The framework's key feature is that rewards depend on the interactions between strategies (see Gibbons, 1992). The predicted outcome is a Nash equilibrium, that is, the combinations of strategies such that no player can improve its payoff by changing its strategy given what other players do. In this article, the players are the universities; the rewards are the total funding of each. Thus, the predicted outcome (Nash equilibrium) will be a strategy for each university such that no university has an incentive to change given what other universities decide to do.

Our game theoretic analysis holds for an arbitrary number of universities, a continuum of strategies, and any level of (positive) funding parameters. The core of the results we obtain depends on the structure of the funding formula. It does not depend on its given parameters. As such, in jurisdictions where these assumptions hold and the incentives we describe are quantitatively important, the strategic outcomes should qualitatively match the findings. For the sake of readability, we also illustrate the results with simple examples.

\section{Simulations}

Our simulations apply the new 2018 Québec funding formula to enrolment data that was observed from 2013 to 2017. Each change from the old formula to the new formula can be introduced and studied separately.

Because of the data available as of August 2018, some adjustments proved necessary. The new formula reorganized the categories of enroled students for the purpose of pricing enrolment in fewer categories. 
Although the reform reduces the number of weighted categories, in a few cases old categories are split into two categories. We performed that split by estimating the total effective proportion to extract from the original category towards the new category, using the proportion of graduates in each field (see Appendix 3). Data on graduates by field, tier and year is publicly available and is precise enough to allow for a reasonable simulation (Québec Government, 2016).

We also approximated some components of the funding formula as unconditional transfers of funds. Roughly $10 \%$ of the Québec formula is based on the size of buildings and related metrics, such as the price of energy. None of the changes affect significantly this portion of the formula. The remainder of the funding formula (roughly $90 \%$ of the public funding) is modeled exactly as announced. For each year studied, we analyzed the funding from Québec official documents (Québec government 2017a, and previous documentation).

We tested our simulation environment with Québec's previous university formula and were able to reproduce the observed budget, save for a few thousand dollars.

We discovered discrepancies in the official government documents, including calculation errors and transcription mistakes. For our purpose, these discrepancies were not frequent, and the mean absolute error is below $1 \%(0.02 \%)$.

Finally, as tuition fees and regulations for international students have not changed for the period studied, we ignore them and focus on the change in public funds. ${ }^{2}$

The official documents' declaration of enroled students changes over time for the same reported year. Since the Québec university formula uses a changing average for student enrolment, we had to choose which year to reproduce in official documents. We chose the most recent.

Note that our approach does not include eventual changes in behaviours induced by policy change. This is a static analysis where the data on student enrolment is left as is. Analysis of the impact of formula changes in Canada remains open for empirical research.

\section{Incentives Analysis}

\section{A Typology of Enrolment-based Formulas}

Our paper focuses on formulas that are dynamically inconsistent (see Table 1). Remember, a funding formula is dynamically consistent when it factors in the appropri- ations required by the incentives it generates. In particular, if the growth of funding does not match the growth of enrolment induced by the incentives of the funding formula, the formula is dynamically inconsistent.

From a design perspective, funding formulas may be unary or binary. Unary formulas determine a total amount per student, including tuition, for a given category of enrolment. The public subsidy is that total amount of cost, minus the tuition fees. Funding formulas that are binary determine an amount of public subsidy independently of any given total-and tuition fees may not be regulated.

In both cases, dynamic inconsistency arises when the public amount per student is not constant over time. The theoretical results that we outline apply to both types of design when they are dynamically inconsistent. However, binary formulas provide flexibility to universities to compensate through tuition adjustments. As such, the implications of these results may be weaker in jurisdictions with such a design.

\section{Enrolment-based Funding Formula}

Equation (1) summarizes the general structure of an enrolment-based funding formula: ${ }^{3}$

$$
\begin{aligned}
S_{i} & =T_{i}+p \sum_{j} w_{j} e_{i j}, \\
& =\underbrace{T_{i}}_{\text {uncond. }}+\underbrace{p\left(w_{1} e_{i 1}+\cdots+w_{m} e_{i m}\right)}_{\text {enrollment based }} .
\end{aligned}
$$

For each university identified by index $i, S_{i}$ designates the total public subsidy given to the university, and $T_{i}$ represents unconditional transfers given to the university. These transfers can vary by university. The term $p$ is the default value of an enroled student; the term $w_{j}$ is the weight given to a specific category of enrolment that varies by category of funding ( $j$ is a running index on those categories). These weights do not vary per funding category, but nothing precludes equation (1) from having university-specific categories. Thus, equation (1) can encompass the analysis of jurisdictions with funding per student that varies by type of institution. The number $e_{i j}$ designates the recorded number of full-time students enroled in category $j$ at university $i$. Hence, the product of the three terms $p w_{j} e_{i j}$ yields the monetary value, for university $i$, of the number of enroled students in category $j$. 
Table 1. A classification of funding formulas according to its consistency and its design

\begin{tabular}{|l|l|l|}
\hline & Unary formulas & Binary formulas \\
\hline $\begin{array}{l}\text { Dynamically } \\
\text { consistent }\end{array}$ & $\begin{array}{l}\text { The total (real) funding per student is } \\
\text { constant over time. }\end{array}$ & The public subsidy per student is constant over time. \\
\hline $\begin{array}{l}\text { Dynamically } \\
\text { inconsistent }\end{array}$ & $\begin{array}{l}\text { The total (real) funding per student varies } \\
\text { through years. }\end{array}$ & $\begin{array}{l}\text { The public subsidy per student varies over time (but } \\
\text { tuition can adjust to partially compensate). }\end{array}$ \\
\hline
\end{tabular}

We remain completely agnostic on how funding categories are designed. They can be divided by tier, by groups of programs, by both, or any other division of enrolment. Equation (1) can fit the cases of Texas (82 funding categories), Québec (39 funding categories), or California (five funding categories for universities) (Gouvernement du Québec, 2017a; University of Texas, 2016; University of California, 2012). For our analysis, what matters is the mathematical structure of equation (1)-the formula-rather than a specific instance.

Choosing a funding formula is thus equivalent to choosing transfers $T_{i}$, weights $w_{j}$, the funding categories with each weight, and the default price $p$. We now address how the baseline price per student $(p)$ is defined. The sum of funds given to each university must equal budget appropriations set aside for the universities' funding:

$$
G=\sum_{i} S_{i}
$$

Equation (2) states that the sum of funds transferred to universities $\left(\sum_{i} S_{i}\right)$ equals the total funds available $(G)$. Dynamic inconsistency arises depending on the direction in which equation (2) is realized. If the sum of subsidies $\left(\sum_{i} S_{i}\right)$ is considered the accurate amount, thus accounting for changes in enrolment, and $G$ is determined consequently, the formula is then dynamically consistent. However, if $G$ is determined independently first, and the baseline price per student $(p)$ is then adjusted so that equation (2) holds, the formula becomes dynamically inconsistent.

From the university's perspective, the total funds include tuition revenues. If we denote the tuition amount of university $i$ in funding category $j$ by $f_{i j}$, then the tuition revenues in that category are given by $f_{i j} e_{i j}$. Hence, the total funding $\left(F_{i}\right)$ is given by:

$$
\begin{aligned}
F_{i} & =S_{i}+\sum_{j} f_{i j} e_{i j}, \\
& =T_{i}+p \sum_{j} \underbrace{\left(w_{j}+f_{i j} / p\right)}_{\text {total weight }} e_{i j} .
\end{aligned}
$$

Box 1 (see next page) provides an example of how the formula works. Equation (3) shows that tuition fees are, in essence, weight modifiers to a funding formula. From a design perspective, the weights $w_{j}$ can be chosen so that the total funding per student $\left(w_{j}+f_{i j} / p\right)$ equals a given value (unary formula) or can be decided independently (binary formula). Our theoretical characterization of universities' behaviour does not depend on any of the binary or unary designs, thus the analysis holds qualitatively in both cases.

However, assessing the relative importance of private and public funds in the total funding matters for a quantitative assessment. Some jurisdictions may have a high proportion of funding that stems from tuition (Ontario, compared to Québec, would be a good example). When only public weights are modified, the difference then is the extent to which public weights affect the total weights (public weights + tuition). Because the effect of public weights on total funding would be smaller, the quantitative change in behaviour could be anticipated as being less important.

\section{Incentives Analysis: Should Universities Seek Growth?}

In this section, we analyze the strategic behaviour of universities.

Proposition 1: Consider an arbitrary number of universities $i=1 . . . n$ funded per equations (1-3). Consider furthermore: a) that they do not coordinate; b) that they seek to increase net revenues; and c) that they each face different costs per additional enroled student $c_{\mathrm{ij}} \geq 0$. Then: 
Box 1: A simplified application of Equation 3

Consider a small university (labelled $i=1$ ) with only 15 students distributed amongst 2 funding categories, say "undergraduate computer science" $(j=1)$ and "masters sociology" $(j=2)$. Category $j=1$ has 5 full-time students $\left(e_{11}=5\right)$ whilst category $j=2$ has $10\left(e_{12}=10\right)$ full-time students.

For the sake of the example, let the funding rule be such that students in category $j=1$ have a unit weight $\left(w_{1}=1\right)$, while students in category $j=2$ are weighted at $2\left(w_{2}=2\right)$.

We further assume that the unconditional transfers total 1 dollar $\left(T_{i}=\$ 1\right)$, that the default price for each student is $\$ 3(p=\$ 3)$, and that tuition fees are uniform at $\$ 1$ per student $(f=\$ 1)$.

In this scenario, the university would receive $\$ 91$ :

$$
\begin{aligned}
F_{i} & =\underbrace{1}_{T_{i}}+(\underbrace{3 \cdot 1+1}_{p \cdot w_{1}+f}) \cdot \underbrace{5}_{e_{i 1}}+(\underbrace{3 \cdot 2+1}_{p \cdot w_{2}+f}) \cdot \underbrace{10}_{e_{i 2}}, \\
& =\$ 91 .
\end{aligned}
$$

1. Any university that has at least one profitable category of funding (i.e.: $p w_{j}>c_{i j}$ ), loses revenues if it does not increase enrolment. As such, the predicted outcome (Nash equilibrium) is that any university facing that condition will increase enrolment;

2. If statement 1 holds and if one university (or more) has no profitable category of program (i.e.: $p w_{j}>c_{i j}$ for all $j$ ), then its share of public funding necessarily declines; and

3. If statement 1 holds and the growth of public funding $(G)$ is smaller than the growth of enrolment (dynamic inconsistency), then the strategic outcome is such that the public funding per student declines. In particular, if public appropriations are constant, universities are in a purely redistributive game for public funds (zero-sum game).

The formal proof of this proposition is in Appendix 1. We discuss five key aspects of the proposition. First, it holds for any number of universities, any funding formula that matches equations (1-3) and any level of tuition fees. The key elements for the results to hold are the assumptions of the proposition: universities seek to increase revenues, they do not cooperate, and there must be at least one category of funding that is more profitable.
When the assumption holds, and when they are quantitatively important, then the predicted outcomes of the proposition should be observed. The qualitatively important qualifier is somewhat subjective. A one dollar increase in net revenues may not warrant a change of strategy by universities. Thus, we view the assumption that universities seek to increase revenues as applying when there is a significant impact.

Second, if at least one university can increase its net income $\left(p w_{j}-c_{i j}\right)$ by increasing enrolment, the predicted outcome is that it will do so. There is a perhaps a subtler notion: this holds when accounting for the adjustment of the default price per student $(p)$ induced by the chosen strategies. In other words, they choose a growth strategy if it is profitable accounting for a possible dynamic inconsistency. Third, if one university cannot increase enrolment because it finds it unprofitable, then it necessarily loses market shares of public subsidies. This part of the proposition conveys a key feature of an enrolment-based formula: enrolment is a necessary condition for growth in the proportion of funding. Fourth, if the growth of total funding is lower than the total growth of enrolment, then the formula is dynamically inconsistent and the university will receive less public funding. A particular case is when funding does not increase at all ( $\mathrm{G}$ is constant). This is already known in the literature as a zero-sum game (Ehrenberg, 2008; Rizzo, 2004). 
The third point of the results shows the importance of dynamic consistency. If equation (2) does not factor in the incentives induced by equation (1) then the public funding per student declines. Fifth, if universities can compensate the decline of public subsidies by adjusting tuition, as within a binary design, the overall impact of the strategic outcome becomes weaker.

We illustrate how the proposition functions with a system of 3 universities $(i=1,2,3)$ and assume 10 students enroled per university (other examples are presented in Appendix 2). Each university's marginal cost of enrolment is given by $c_{1}=1.8, c_{2}=0.5, c_{3}=0$. The funding formula is tiered, in the sense that it provides more funding per student in university 2 than in universities 1 and 3 . There are thus two funding categories $(j=1,2)$ : one for university two $\left(w_{2}=10\right)$, and another one for the other two universities $\left(w_{1}=1\right)$. As such, enrolment per category is $e_{11}=e_{31}=10, e_{22}=10$ (and zero elsewhere). Tuition fees are set to unity $(f=1)$, total public funding is set to one hundred units $(G=100)$ and unconditional transfers are set to zero $\left(T_{1}=T_{2}=T_{3}=0\right)$. Because appropriations are assumed to be constant, there is dynamic inconsistency. Each university can choose a growth strategy, increasing enrolment by one student ( $10 \%$ increase), or a continuity strategy, where no enrolment occurs. The interactions between each university are shown in Table 2 . The first two columns display the outcomes when university 3 keeps a continuity strategy, while the last two columns show when university 3 chooses growth. Each cell, which represents the outcomes of a particular scenario, presents the net revenues for universities $\left(N R_{1}, N R_{2}, N R_{3}\right)$ and the total public subsidy awarded $\left(S_{1}, S_{2}, S_{3}\right)$. The evolution of public subsidies awarded per student is shown with the baseline price per student $(p)$. The Nash equilibrium (predicted outcome) is shown in light blue.

Note that by construction, the Nash equilibrium is such that no university has any incentives to choose another strategy, given what other universities do. As such, university 1 chooses the continuation strategy. This is because a growth strategy, considering what other universities chose, worsens its finances. In concordance with proposition 1 , its share of the public subsidy decreases. Because the growth of enrolment is higher than the growth of funds, the third part of proposition 1 tells us that university 1 loses net revenues as well. Since its marginal revenues are higher than the marginal costs, university 2 benefits from a growth strategy and so does university 3.

Some comments are needed here. First, our analysis is silent on the (un)desirability of a decrease in public funding per student. To address this, one would have to analyze how total finances and quality evolve. The most likely scenario is that the quality of teaching decreases with a decrease in total funding per student. If this happens, there is a trade-off for society. The formula favours accessibility, but the dynamic inconsistency then yields

Table 2. Growth strategies

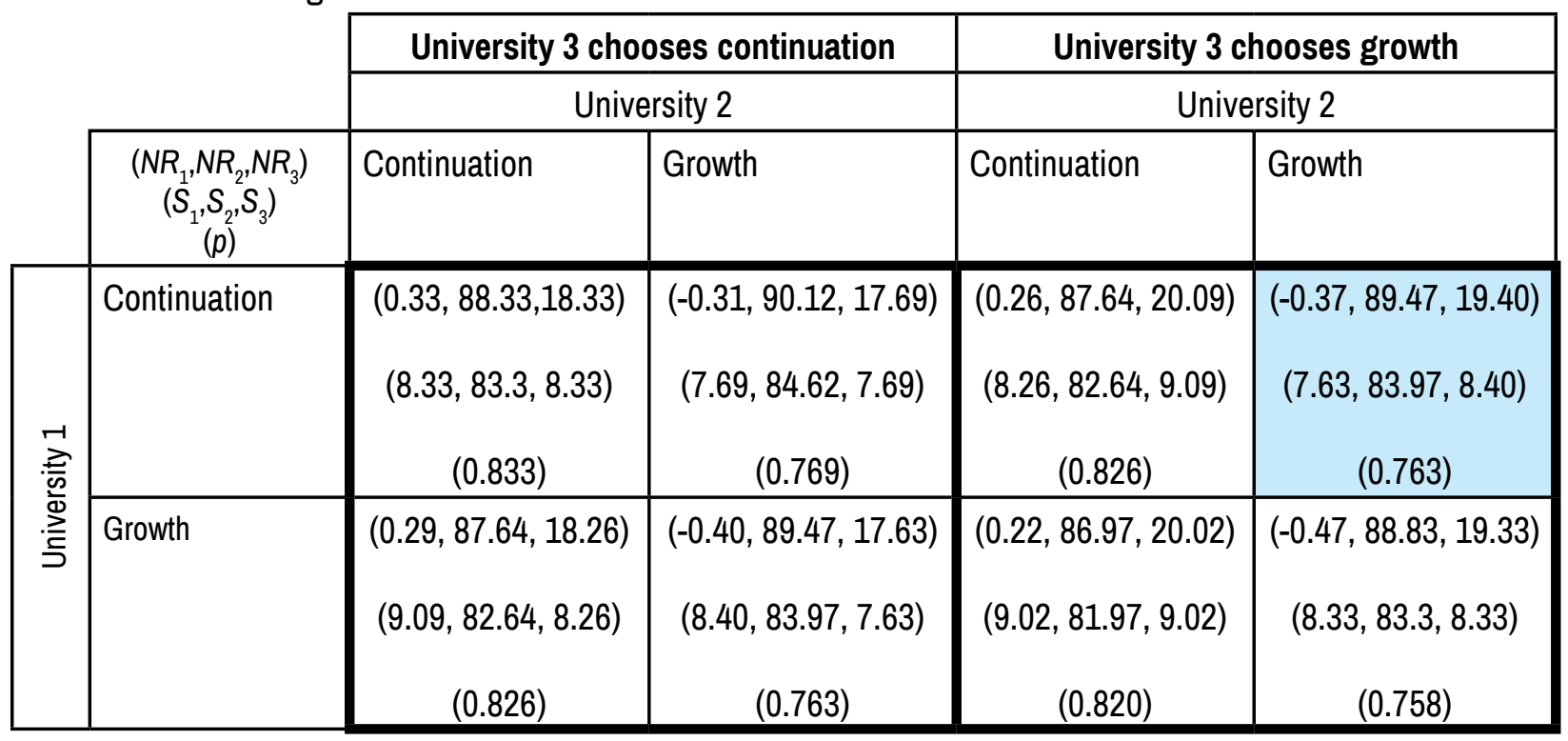

Note: the Nash equilibrium is in light blue. Numbers are rounded, real calculations may differ up to a rounding error. 
lower quality. Second, the predicted outcome (Nash equilibrium) changes if we assume that universities seek to maximize revenues per student. Then, the predicted behaviour is not clear, but can include the status quo if unconditional transfers are important.

In Appendix 2, we provide two additional examples: a system of two identical universities with no tuition fees, and a system of two universities with high tuition fees. The qualitative results are the same as in the previous example.

\section{Incentives Analysis: Substitution Strategy}

An enrolment-based funding formula generates other incentives. If there are more than two categories of funding and if one of them yields higher net revenues than the other, then universities face incentives to substitute (shift) enrolment from the low-weighted category to a high-weighted category. This leads to the second proposition below.

Proposition 2: Consider an arbitrary number of universities $i=1$...n funded per equations $(1-3)$ and the same assumptions $(\mathrm{a}-\mathrm{c})$ as in Proposition 1 . Then:

1. Any university that has at least one category of funding that is more profitable than another (i.e.: $p w_{j}-c_{i j}>p w_{j}-c_{i j}$ for $\left.j \neq j^{\prime}\right)$ loses revenues if it does not substitute enrolment. As such, the predicted outcome (Nash equilibrium) is that any university facing that condition will seek to substitute enrolment;

2. If statement 1 holds for at least one university while (some) other universities have no such condition, then the share of total funding necessarily declines for the latter; and

3. If statement 1 holds and the growth of total funding $(G)$ is smaller than the growth induced by substitution (dynamic inconsistency), then the strategic outcome is such that the total funding per student declines.

The mathematical proof is in Appendix 1. As soon as at least one university has a more profitable category of funding, the predicted outcome of the game is a substitution effect between categories of funding. A university is better off by simply reducing enrolment in the least profitable category and by shifting enrolment in the second one. However, we remain agnostic on how this can be done (or whether it is desirable). But one can imagine several ways this can be done, ranging from real changes in enrolment to the relabeling of courses, so that the underlying enrolment becomes accounted for in the profitable category. Whether these examples can be implemented depend on the degree of autonomy of universities. The remaining results of the second proposition are the same as those of the first one.

We illustrate the proposition with a two-universities environment where total funding remains equal to one hundred units $(G=100)$. We determine these values for the sake of simple mathematics; they could be numerically different, and the logic would still hold. We set unconditional transfers to ten units $\left(T_{1}=T_{2}=10\right)$, and neglect marginal costs and tuition fees $\left(c_{i j} \approx 0, f_{i j} \approx 0\right)$ as those elements provide no insights. To have a meaningful discussion, however, we need at least two funding categories with different weights. We set category $j=1$ to a value of $1\left(w_{1}=1\right)$ and category $j=2$ to $10\left(w_{2}=10\right)$. We set total enrolment to 44 students in each university: 40 students in category $j=1\left(e_{11}=e_{21}=40\right)$, and 4 students in category $j=2\left(e_{12}=e_{22}=4\right)$. The two universities can choose between two strategies: a continuity strategy of keeping the same enrolment for each category, or a substitution strategy, where 10 enroled students can be shifted from category $j=1$ to category $j=2$. Proposition 2 tells us that because category 2 is more profitable, universities will switch enrolment accordingly. Furthermore, because total funding is fixed, this is a zero-sum game.

The environment is presented in Table 3 and follows the same convention as Table 2. This environment can be generalized to any number of universities; but for presentation purposes we kept that number at two. Since the design of this example is such that net revenues are equal to public subsidies, only the latter are presented.

The top-left cell is the funding outcome if both universities choose continuity. However, if one university adopts a substitution strategy (top-right or bottom-left cells), it gains 14.4 units in funding. This increase is the result of an enrolment shift in the higher-weighted category. Finally, if both universities adopt the substitution strategy, there is no gain (bottom-right cell) and the public funding per student $(p)$ plummets.

Some comments are needed. First, substitution strategies are always rewarding, regardless of dynamic inconsistency, if universities keep the same underlying cost structure. In other words, it is always profitable to misrepresent enrolment from lower rewarding funding categories towards more rewarding ones. Second, in 
Table 3. Substitution strategies

\begin{tabular}{|c|c|c|c|}
\hline & & \multicolumn{2}{|c|}{ University 2} \\
\hline & $\begin{array}{c}\left(S_{1}, S_{2}\right) \\
(p) \\
\end{array}$ & Compliance & Substitution \\
\hline \multirow{2}{*}{.7 } & Compliance & $\begin{array}{c}(50,50) \\
(0.5)\end{array}$ & $\begin{array}{c}(35.6,64.4) \\
(0.32) \\
\end{array}$ \\
\hline & Substitution & $\begin{array}{c}(64.4,35.6) \\
(0.32)\end{array}$ & $\begin{array}{c}(50,50) \\
(0.32)\end{array}$ \\
\hline
\end{tabular}

Note: the Nash equilibrium is in light blue. Numbers are rounded, real calculations may differ up to a rounding error.

practice, the option that a university has for substituting students from one category to another depends on the categories of programs offered. Specific-vocation universities, such as engineering or business schools, can hardly substitute students in program categories they do not have. Finally, the government can reduce incentives for substitution by weighting categories uniformly to their marginal cost (assuming they are constant). Such a formula would eliminate substitution incentives based on costs. However, they would generate incentives to mislabel enrolment from one category to another. Thus, a trade-off that faces a policy maker is between small (and accurate) funding categories and larger (but hard to cheat in) categories.

\section{Simulation of the Québec Reform}

This section explores the impacts of the May 2018 Québec reform (Gouvernement du Québec, 2018b). We examine the impact of the new formula based on the 2013-2017 enrolment data, simulating cumulatively each element announced in the reform. We show how the new formula works in Québec and what effects could be anticipated for each university. ${ }^{4}$

\section{Specificity of Québec's Funding Formula}

The Québec government uses a unary design, meaning that the total funding is fixed in its first year. However, the formula is dynamically inconsistent. The total amount of appropriations $(G)$ is calculated independently in the following years, and the default price $(p)$ is adjusted to match enrolment patterns. Thus, as defined in Table 1 , the Québec funding formula is unary and dynamically inconsistent. Québec uses the notion of full-time equivalent (FTE) student to measure enrolment per university. A major difference between Québec's formula and equation (1) is the use of a moving average to mitigate important losses in enrolment in a given year. This moving average is not applied if enrolment increases. Thus, universities always get the best of both outcomes.

If roughly $71 \%$ of public funding is channeled through enrolment, approximately $12 \%$ is tied to building size (in square meters) and other related inputs (Table 4). These are assumed to be fixed in our simulations. The remainder of the funds are channeled through unconditional transfers, some being targeted for specific universities. Some minor performance-based components do exist, such as bonuses for having no deficits, or penalties if strikes occur.

\section{Changes to the Québec Funding Formula}

The Québec government announced four main changes to its university funding formula. First, categories used for weighting were reduced from 72 to 39 . Accordingly, the government introduced new weights for the revamped funding categories. Second, a temporary redistributive measure was introduced to mitigate the new formula's negative impacts on some universities. The measure capped the funding growth induced by the change at $5 \%$ to redistribute the loss to universities that faced de- 
Table 4. Variables of Québec PSE formula (2017-2018)

\begin{tabular}{|l|l|l|l|l|}
\hline & Student-based fund & Fields and buildings & \multicolumn{1}{|l|}{$\begin{array}{c}\text { Unconditional } \\
\text { universal fund }\end{array}$} & \multicolumn{1}{|c|}{$\begin{array}{c}\text { Unconditional } \\
\text { specific fund }\end{array}$} \\
\hline Funding (\$k) & $2,111,189.1$ & $343,515.0$ & $52,702.0$ & $454,379.5$ \\
\hline Proportion (\%) & 71,3 & 11,6 & 1,8 & 15,3 \\
\hline
\end{tabular}

Source: Québec Government (2017a) and calculations.

creased revenues. This measure will remain active for as long as some universities lose some funding under the new formula. As accrued funding will come into effect over years, the measure will vanish. Third, the base price per student $(p)$ was changed, notably to reflect the changes of funds channeled through the enrolment-based component of the formula:

1. The government announced an increase in appropriations up to a total of $\$ 105.2$ million; and

2. The government slashed $\$ 188.6$ million of unconditional transfers.

Finally, two additional unconditional transfers (the component $T_{\mathrm{i}}$ ) were introduced: funds totalling $\$ 6.3$ million for small regional universities, and a specific transfer for engineering schools and faculties, which are the most negatively impacted by the revised weights.

\section{Simulations of Changes}

Figures 1 to 4 present the main findings of our simulations. For the sake of clarity each graph shows the impact of the reform only for universities that were the most affected (see Appendix 3 for complete graphs). The changes are displayed as a percentage of the original funding.

Figure 1 presents the sole impact of the changes in categories and weights. Hence, it shows how the change in the weighting grid works in the redistributing of funds. Except for UQAT and the two engineering schools (Polytechnique, École de technologie supérieure [ÉTS]), the variations in budgets are within $5 \%$ of the funding under the original formula. The flat line is Université du Québec's headquarters (UQSS). As it has no enroled students, there are no changes in its funding. Above the flat line are eleven universities who structurally benefitted from the modification (only UQAT is shown). Within Université du Québec's network, five universities are structurally penalized: the two engineering schools, École nationale d'administration publique (ÉNAP) and two other universities (not shown). Although not shown, McGill University and Université de Sherbrooke are large institutions that pay for most of the redistribution. However, the two engineering schools are the most affected by the changes in weights. More than $10 \%$ of their budget is lost.

Figure 2 presents the cumulated effects of the changes in weights, the additional $\$ 105.2$ million and the redirection of the $\$ 188.5$ million in the enrolment-based component of the formula. The unconditional transfers and the redistributive mechanism limiting growth are left out. We interpret Figure 2 as showing the long-term impacts of the new formula: the true redistributive effects of the formula, once the growth-limiting mechanism vanishes. Since the government announced more funds ( $\$ 105.2$ million), most universities' budgets increase. However, ÉTS and Polytechnique remain penalized. At the other end of the range, three universities largely benefit from the modifications (only ÉNAP is shown). A vast majority of institutions benefitted slightly from the influx of money.

Figure 3 presents the combined effects of the previous measures and additional unconditional transfers. We exclude the growth limiting mechanism. Note that the principal change is accrued funding for engineering schools and UQAT.

Figure 4 represents the effect of all the measures and shows the effects of the reform, including the shortterm effects. The curves shown in Figures 3 and 4 exhibit the same tendency, but a general shrinking of the variations is observable in Figure 4. In Figure 3, there are some variations between $-30 \%$ (ÉTS) and $+50 \%$ (ÉNAP), whilst, for the same universities, figure 4 shows variations of $-20 \%$ and $+50 \%$. The growth limitation mechanism thus has some effect. 


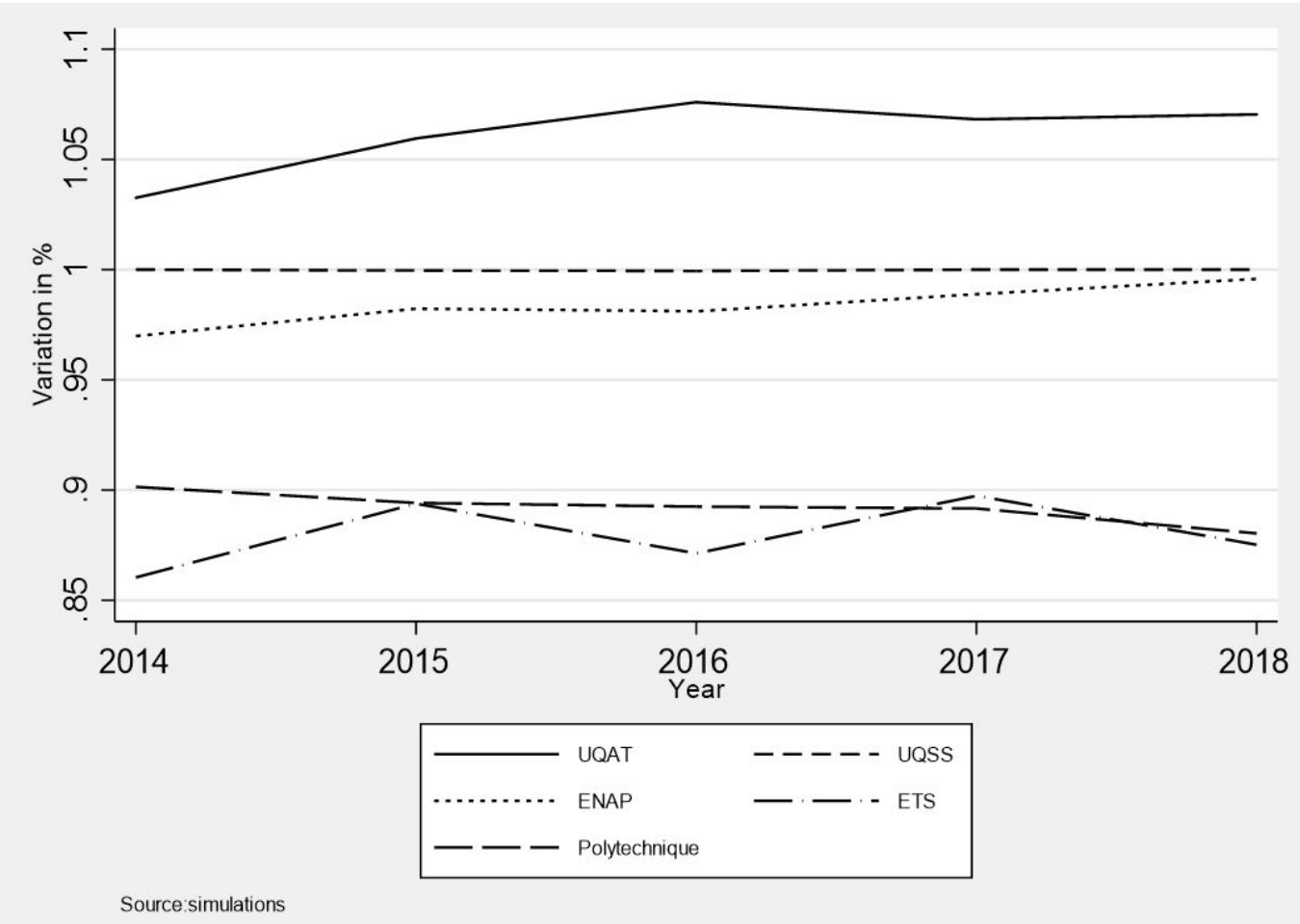

Figure 1. Weighting grid modification from CLARDER to CAFF

Note: only UQAT, ENAP, UQSS, ETS and Poly are shown. See Appendix 3 for the complete graph.

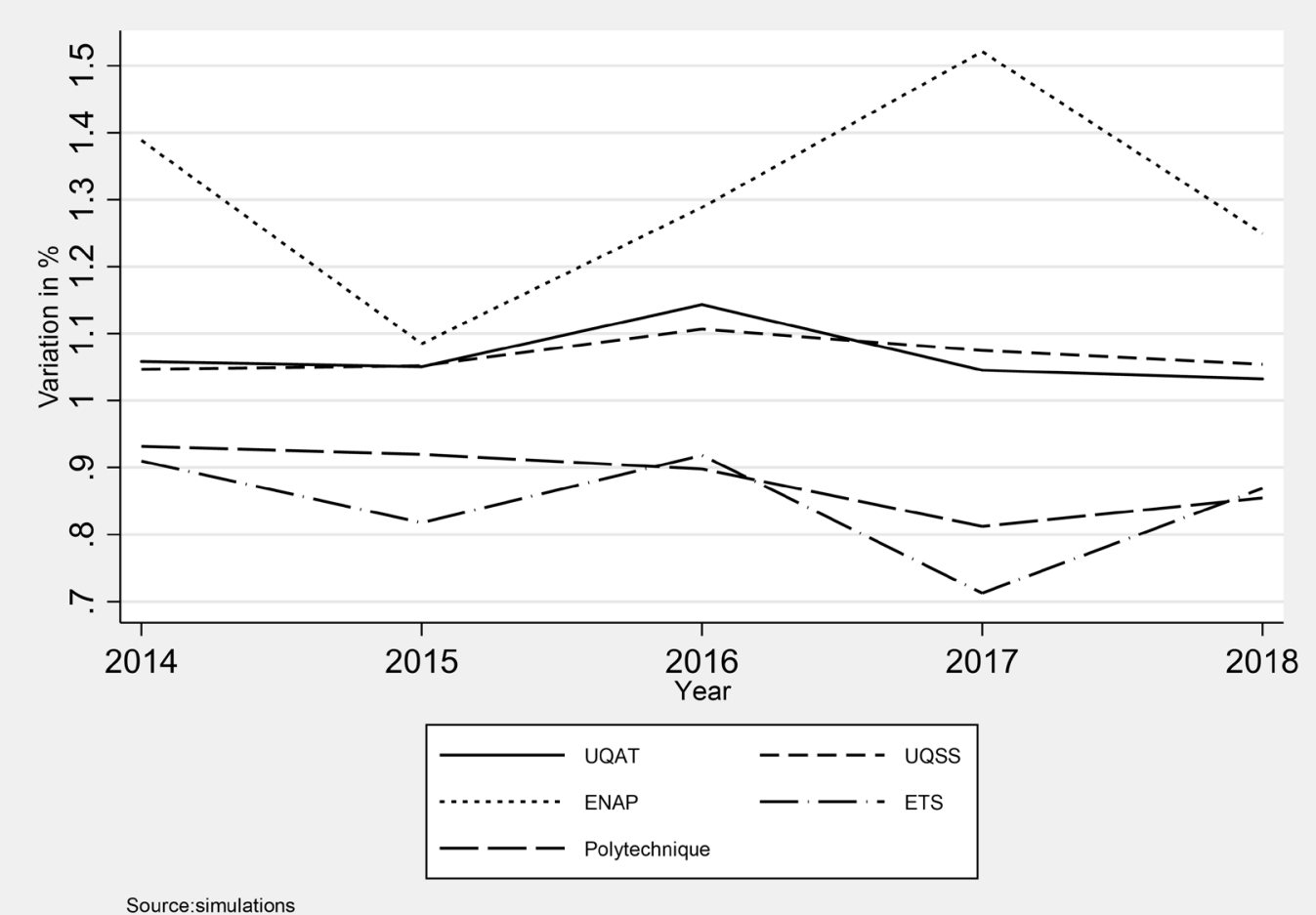

Figure 2. 2018-2019 budgets with no growth or redistributions mechanisms Note: only UQAT, ENAP, UQSS, ETS and Poly are shown. See Appendix 3 for the complete graph. 


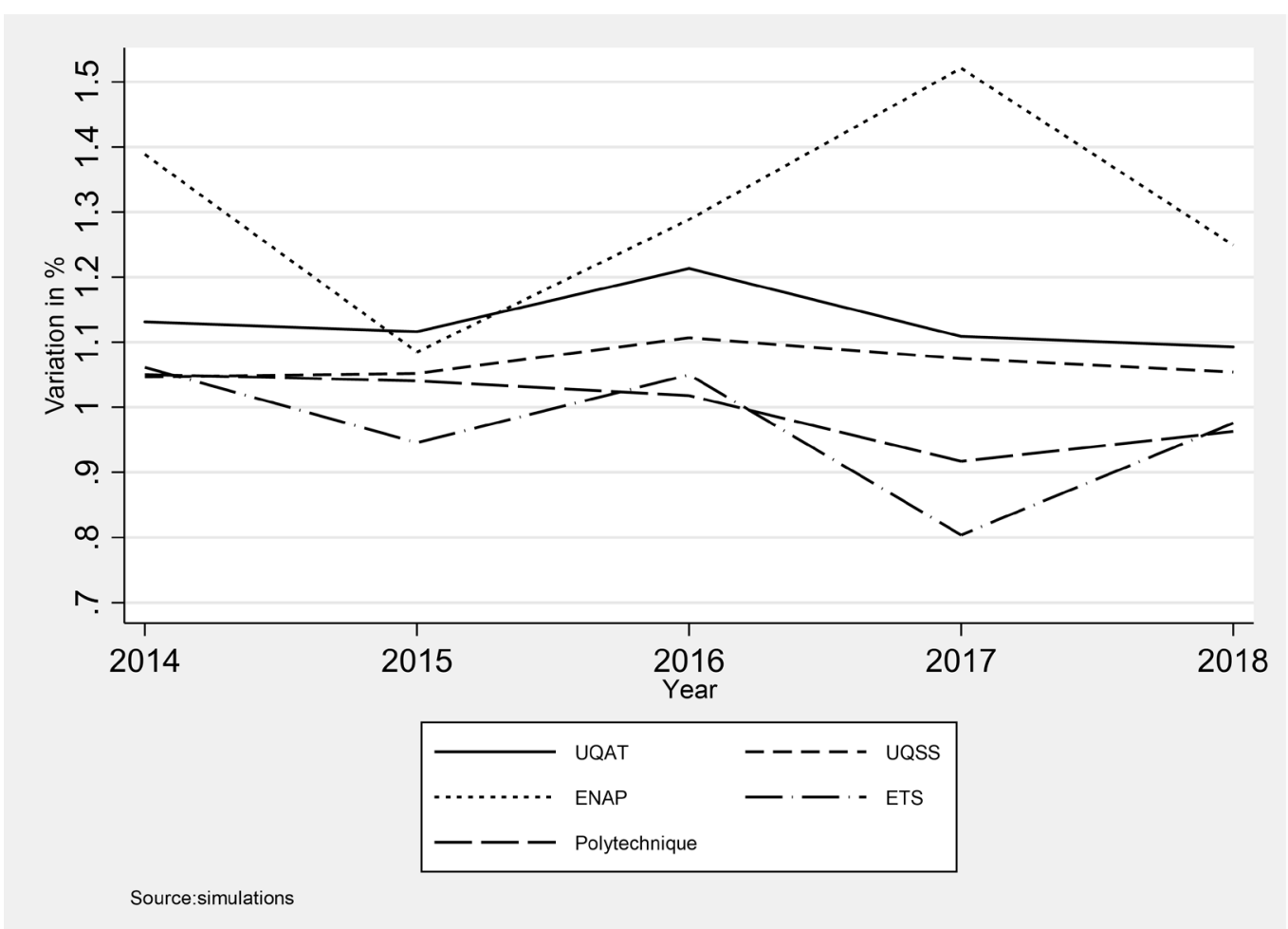

Figure 3. 2018-2019 budgets with no growth but with redistributions mechanisms. Note: only UQAT, ENAP, UQSS, ETS and Poly are shown. See Appendix 3 for the complete graph.

\section{Policy Design and Analysis}

We summarize below what one can conclude from our analysis for the purpose of policy.

\section{Weights Form a Relative Price System}

An original intent of most enrolment-based formulas is to introduce different weights (indicators of value) to reflect the difference in costs. This conception of funding assumes that universities are unaffected by incentives. However, two reasons suggest the opposite. First, the weights assigned by the funding formulas may be based on average costs across universities, or in general may not be equal to a university specific marginal cost of enrollment. This difference then creates profitability for some funding categories, which is the basis of our theoretical analysis. Second, empirical results also suggest that universities do respond to changes in the formula. Universities can substitute students from one category to another, increase or decrease enrolment, and so on. In some jurisdictions, they can even adjust tuition. These reactions change the effective funding per student in each category, thus reducing the connection between the costs embedded in weights and the effective funding of programs. In other words, the observed marginal costs per student are not exogenous, but rather a function of the behaviour induced by funding formulas. We think that a more robust approach in thinking about funding weights is as indicators of value to steer enrolment. The weights signal where there is a change in profitability.

In the Québec 2018 reform, the weights for most of the PhD-level enrolment went from $6.4(\sim 23,000$ per FTE) in 2017 to 10.4 ( $\$ 42,000$ per FTE) in 2018. Although this would be surprising, it is possible that marginal costs per student were miscalculated by $80 \%$ in the previous version of the formula. Alternatively, it is very well possible that the policy makers are simply signaling their desires to see an increase in PhD enrolment. We do not presume which of the two prevails; we simply argue that the results will be the same in both cases, as we ultimately get an increase in price. That is, an increase in $\mathrm{PhD}$ enrolment can be expected, despite placement problems that may (already) exist (Dehaas, 2014). 


\section{Changing the Weighting Grid Mostly Redistributes Funds}

Modification in the weighting grid modifies how funds are distributed to each university. Given a fixed budget, weight modification affects structural advantages of some universities over others.

In order to mitigate the effects induced by the Québec reform, the government introduced some dampening mechanisms that will disappear over time. Their gradual elimination will reveal the structural real gaps between institutions. We present these gaps in Figure 5 for each university (in 2018 only). This graph shows successively each budget measure for each university. In order to demonstrate the gaps, the horizontal axis shows relative impacts on university budgets. The first two columns show the permanent advantages. In 2018, twelve universities benefitted from the change in the weights. At the other end of the range, four universities were disadvantaged. Considering the overall trends (see Figure 4 in Appendix 3), 15 universities benefitted from the reform whilst only HEC Montréal is at a disadvantage (the remaining three have mixed results).

\section{Reducing Categories Used for Weighting Minimizes Substitution Incentives}

Since universities are free to choose where they allocate funds among programs, one can reduce funding-formula complexity by reducing the number of weighted categories. The most notable benefit of doing so is the eradication of the possible substitution effects based on enrolment categories, which in turn reduces the need for a detection and compliance program. By going from 72 to 39 categories used for weighting, Québec's reform effectively reduced substitution effects among programs with similar courses. The programs that are regrouped within funding categories do not seem to be random choices, but seem based on similarities within programs.

\section{An Unconditional Component Protects Universities from Decreases in Student Enrolment}

Demographic projections show a general decline of the 18-24 year old population in Québec for the planning horizon up to 2025 (Gouvernement du Québec, 2017b).

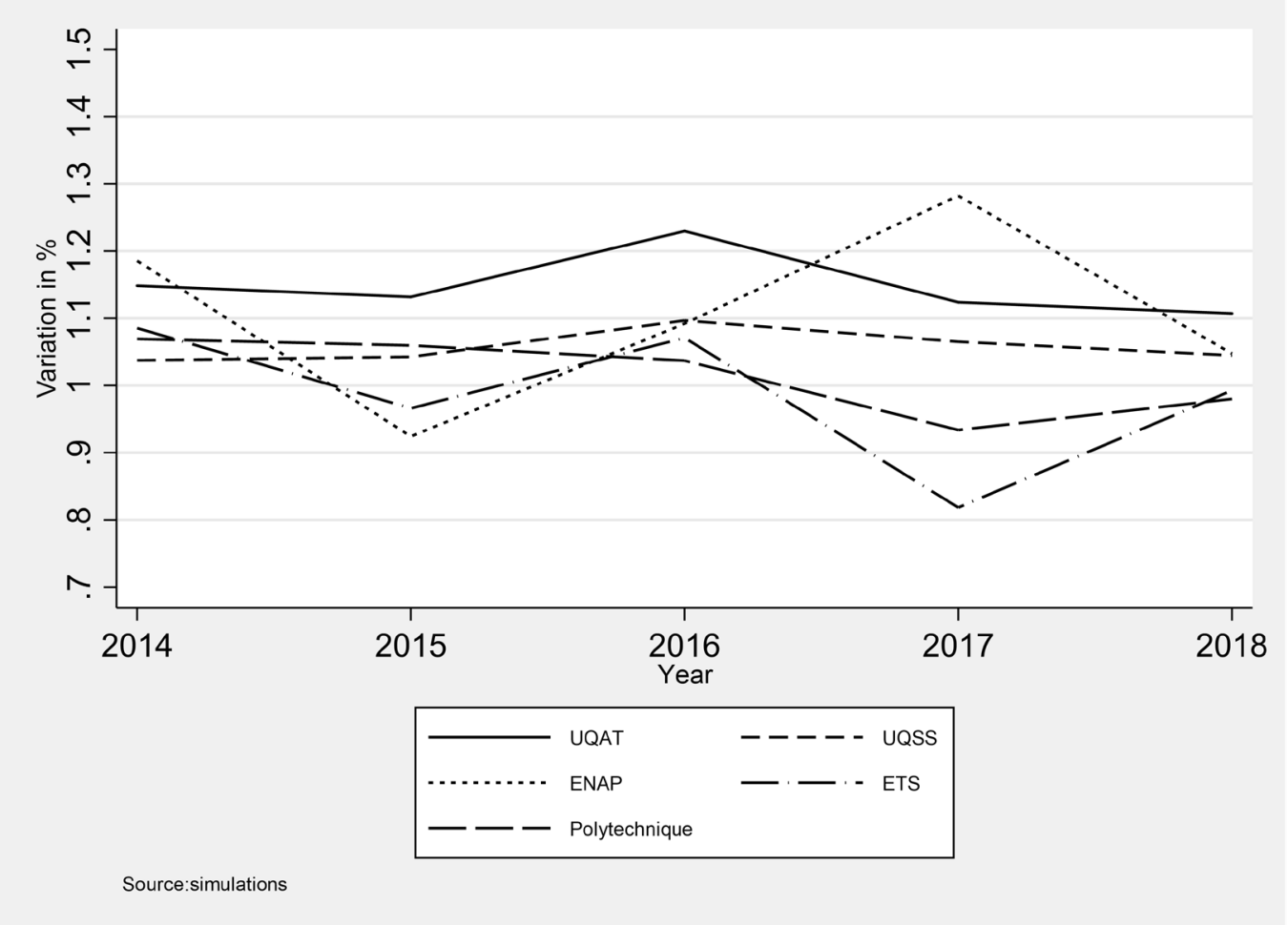

Figure 4. Global reform effects

Note: only UQAT, ENAP, UQSS, ETS and Poly are shown. See Appendix 3 for the complete graph. 


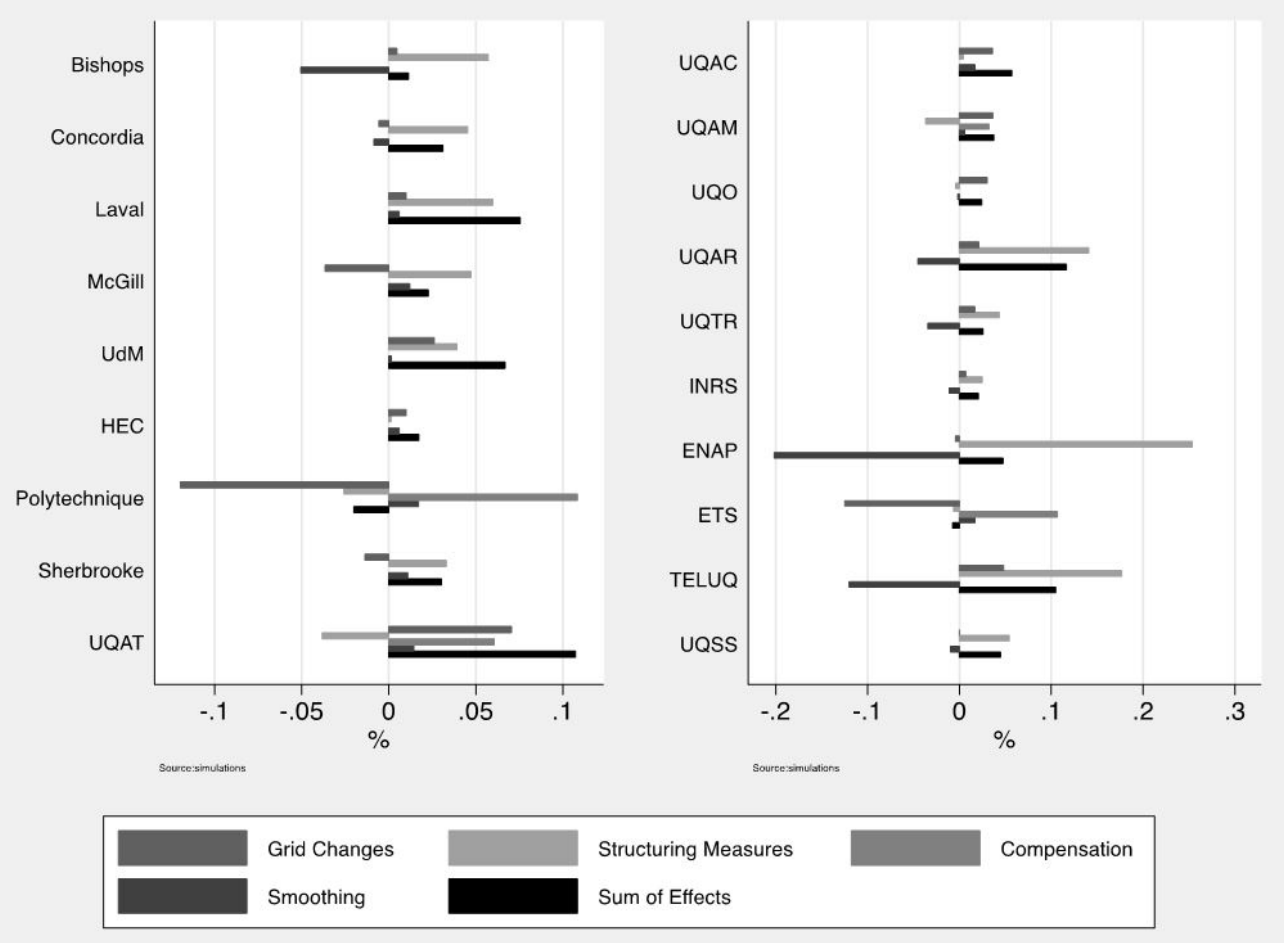

Figure 5. Marginal effects of 2018 reform - synthesis

The universities that are the best protected from a general decline in enrolment are those with a higher proportion of unconditional transfers.

\section{Conclusion}

Enrolment-based formulas produce incentives to recruit additional students. If the formula weights vary from one funding category to another, they also produce incentives for substitution. If the growth rate of funding is smaller than the growth rate of enrollment induced by the formula, a phenomenon we call dynamic inconsistency, then funding per student decreases. Our study of the latest Québec reform suggests that one aim of that reform is to reduce these substitution incentives by compressing 72 categories into 39 . An effect of the reform is a change in the resulting weights, which generates some structural redistribution.

Because the Québec reform also introduces shortand long-term mechanisms, the immediate consequences of the reform are not the same as consequences in the long run. One measure is a short-term mechanism that limits the deeper redistributive effects of the formula. Consequently, the short-term benefits that some universities have early on can degrade over time.
From research on funding formulas, two questions remain open. On what scale can the incentives discussed quantitatively affect the behaviour of Canadian universities? If, in designing a funding formula, university responses are factored in, on what normative grounds can a policy be deemed efficient? These questions are still open and should be the subject of future work.

\section{Acknowledgements}

The authors are grateful to the two anonymous reviewers for their comments and suggestions. They would also like to thank Denis Marchand, Lucie Raymond-Brousseau, Guillaume Dumais, Hugo Morin, Yannick Wilfred Tadjiogue Ogoumfo, Olivier Bégin-Caouette, Deanna Rexe, Martin Maltais, Nicolas Marceau, and Maryse Tétreault for their suggestions and edits. All errors remain our own.

\section{References}

Carpentier, V. (2018). Expansion and differentiation in higher education: The historical trajectories of the UK, the USA and France. Working Paper No. 33. London, UK: Centre for Global Higher Education. 
Retrieved from https://www.researchcghe.org/publications/working-paper/expansion-and-differentiation-in-higher-education-the-historical-trajectories-0 f-the-uk-the-usa-and-francel

CD Howe Institute. (2006). The future is not what it used to be: Re-examining provincial post-secondary funding mechanisms in Canada. Retrieved from C.D. Howe Institute website: https://www.cdhowe.org/public-policy-research/ future-not-what-it-used-be-re-examining-provincial-postsecondary-funding-mechanisms-canada

CEO Student-Centered Funding Formula Taskforce (CEO). (2018). Higher education funding formulas by state (October draft). Retrieved from https:/l www.ccleague.org/sites/default/files/images/higher education funding formulas by state.pdf

De Fraja, G., \& Iossa, E. (2002). Competition among universities and the emergence of the elite institution. Bulletin of Economic Research, 54(3), 275293. https://doi.org/10.1111/1467-8586.00153

Dehaas, J. (2014, May). When Ph.D.s realize they won't be professors. Maclean's. Retrieved from https:ll www.macleans.ca/work/jobs/phds-realize-theywont-be-professors-now-what/

Del Rey, E. (2001). Teaching versus research: A model of state university competition. Journal of Urban Economics, 49(2), 356-373. http://www.doi. org/10.1006/juec.2000.2193

Dougherty, K., \& Reddy, V. (2011). The impacts of state performance funding systems on higher education institutions: research literature review and policy recommendations (CCRC Working Paper No. 37). Retrieved from Community College Research Center website: https://ccrc.tc.columbia.edu/publications/impacts-state-performance-funding.html

Ehrenberg, R. G. (2008). What's happening to public higher education? The shifting financial burden. Baltimore, MD: Johns Hopkins University Press.

Frølich, N. (2006). OECD: Funding systems and their effects on higher education systems, Norway. Retrieved from OECD website: www.oecd.org/norway/38308044.pdf

Frølich, N., Schmidt, E. K., \& Rosa, M. J. (2010). Fund- ing systems for higher education and their impacts on institutional strategies. International Journal of Educational Management, 24(1), 7-21.

Geuna, A. (2001). The changing rationale for European university research funding: Are there negative unintended consequences? Journal of Economic Issue, 35(3), 607-632.

Gibbons, R. (1992). Game theory for applied economists. Princeton, NJ: Princeton University Press.

Gouvernement du Québec. (2016). Diplômes émis à l'enseignement universitaire selon diverses variables, Québec. Retrieved from http://www.bdso. gouv.qc.ca/pls/ken/ken213 afich tabl.page tabl?p iden tran=REPERCOT9JJ24166712999353J1J3X\&p lang $=1 \& p \mathrm{~m}$ 0=MEES\&p id ss dom$\underline{n=1098 \& p \text { id raprt }=3420}$

Gouvernement du Québec. (2017a). Règles budgétaires et calcul des subventions de fonctionnement aux universités du Québec: Année universitaire 20172018. Retrieved from http://www.education.gouv. qc.ca/fileadmin/site web/documents/enseignement-superieur/universitaire/Regles budgetaire universites 2018-2019.pdf

Gouvernement du Québec. (2017b). Prévisions de l'effectif étudiant universitaire (EEETP), par cycle et provenance. Retrieved from http://www.education.gouv.qc.ca/fileadmin/administration/librairies/ documents/Ministere/acces info/Statistiques/ Effectif etudiant universitaire/Previsions ensemble des universites aux fins de fonctionnement 2016-202....pdf

Gouvernement du Québec. (2018a). Le gouvernement conclut une entente avec l'ensemble des universités Québécoises pour moderniser leur financement. Retrieved from http://www.education.gouv.qc.ca/salle-de-presse/communiques-de-presse/detail/article/ le-gouvernement-conclut-une-entente-avec-lensemble-des-universites-quebecoises-pour-moderniser-leurl

Gouvernement du Québec. (2018b). Nouvelle politique de financement des universités. Retrieved from http://www.education.gouv.qc.ca/fileadmin/site web/ documents/enseignement-superieur/universitaire/ Politique-financement-universites-Faits-saillants.pdf 
Hearn, J. C. (2015). Outcomes-based funding in historical and comparative context. Retrieved from Lumina Foundation website: https://www.luminafoundation.org/files/resources/hearn-obf-full.pdf

Higher Education Quality Council of Ontario. (2015). The Ontario university funding model in context. Retrieved from http://www.hegco.ca/SiteCollectionDocuments/Contextual\%20Background\%20to\%20 the\%200ntario\%20University\%20Funding\%20 Formula-English.pdf

Hillman, N. (2016). Why performance-based college funding doesn't work: College completion series: Part four. Retrieved from the Century Foundation website: https://tcf.org/content/report/why-performance-based-college-funding-doesnt-work/?ses$\underline{\text { sion }=1}$

Jones, G. A. (2004). Ontario higher education reform, 1995-2003: From modest modifications to policy reform. The Canadian Journal of Higher Education, 34(3), 39-54.

Jongbloed, B. (2010). Funding higher education: A view across Europe. Brussels, Germany: European Centre for Strategic Management of Universities (EMSU). Retrieved from Uniko Österreichische Universitätenkonferenz website: https://uniko. ac.at/modules/download.php?key=4488

$\mathrm{DE}$ O\&CS $=8 \mathrm{E} 8 \mathrm{~B}$

Khinda, N. (2014). Funding frameworks: Understanding the methods used to finance post-secondary education in Canada. Edmonton, AB: Council of Alberta University Students. Retrieved from https://www. caus.net/funding-frameworks-review

Lahr, H., Pheatt, L., Dougherty, K., Jones S., Natow, R., $\&$ Reddy, V. (2014). Unintended impacts of performance funding on community colleges and universities in three states (CCRC Working Paper No. 78). Retrieved from Community College Research Center website: https://ccrc.tc.columbia.edu/publications/unintended-impacts-performance-funding.html

Layzell, D. T. (2007). State higher education funding models: An assessment of current and emerging approaches. Journal of Education Finance, 33(1), 1-19. https://www.press.uillinois.edu/journals/jef. html
McKeown, M. P., \& Layzell, D. T. (1994). State funding formulas for higher education: Trends and issue. Journal of Education Finance, 19(3), 319-346. https://www.press.uillinois.edu/journals/jef.html

McPherson, M. S., \& Schapiro, M. O. (2006). US higher education finance. In Handbook of the economics of education (vol. 2, pp. 1403-1434). Amsterdam, the Netherlands: Elsevier Science. Retrieved from https://doi.org/10.1016/S1574-0692(06)02024-1

MGT of America. (2011). Nevada system of higher education: Evaluation of the NHSE funding formula. Retrieved from Nevada System of Higher Education website: https://nshe.nevada.edu/wp-content/ uploads/NSHE Funding Formula Report MGT May 2011.pdf

Meek, L. V. (1991). The transformation of Australian higher education from binary to unitary system. Higher Education, 21, 461-494.

Miller, T. (2016). Higher education outcomes-based funding models and academic quality. Retrieved from Lumina Foundation website: https://www. luminafoundation.org/files/resources/ensuring-quality-1.pdf

Moore, A., \& Russ-Eft, D. (2016). Outcomes-based funding: Origins and implications for the SEM practitioner. Strategic Enrolment Management Quarterly, 3(4), 261-281. https://doi.org/10.1002/sem3.20074

Organisation for Economic Co-Operation and Development. (2017). Education policy outlook. Retrieved from http://www.oecd.org/education/policyoutlook. $\underline{\mathrm{htm}}$

Rizzo, M. J. (2004). A (less than) zero sum game? State funding for public education: how public higher education institutions have lost (CHERI Working Paper No. 52). Retrieved from http://digitalcommons.ill. cornell.edu/student/8/

Umbricht, M. R., Fernandez, F., \& Ortagus, J. C. (2017). An examination of the (un)intended consequences of performance funding in higher education. Educational Policy, 31(5), 643-673. https://doi. org/10.1177/0895904815614398

University of California. (2012). University of California rebenching budget committee (Technical Report). 
Retrieved from https://senate.universityofcalifornia. edu/ files/underreview/Rebenchingreviewpacket. pdf

University of Texas. (2016, May). Texas public higher education: Overview of funding formulas for institutions of higher education. Presentation given to Senate Higher Education Committee Legislative Budget Board Staff. Retrieved from https://www. lbb.state.tx.us/Documents/Publications/Presentation/1982 Formula Funding Overview Presentation.pdf

\section{Contact Information}

Pier-André Bouchard St-Amant

École Nationale d'administration publique

Pier-andre.bouchardst-amant@enap.ca

\section{Notes}

1 Although of central practical importance, we set aside the discussion of what constitutes an appropriate value of indexation for the purpose of keeping real funding (as opposed to nominal funding) constant.

2 During the period of study chosen for statistical analysis, the funding formula is such that international students are included (counted) as "in jurisdiction" students for funding purposes. Although universities must charge the higher, state-regulated tuition fees, those revenues are subtracted by the government. Thus, from an incentive standpoint, and for the selected period of study, international students are equivalent to "in jurisdiction students."

3 There are variations to this formula, so the magnitude of the incentives discussed in this paper may vary by jurisdiction. For instance, the Québec funding formula is based on the enrolment average over the last three years. In Ontario and California, the formula is tied to enrolment if it is within a given interval. Although they quantitatively affect the incentives, we neglect these differences and focus on qualitative results.

4 See Gouvernement du Québec (2017a) for acronyms and names of Québec universities. 


\section{Appendix 1. Mathematical Derivations}

\section{Proposition 1:}

Substituting (1) in (2) gives:

$$
G=\sum_{i} T_{i}+p\left(\sum_{j} w_{j} e_{i j}+\sum_{i \neq \neq} \sum_{j} w_{j} e_{i \prime j}\right)
$$

which implies:

$$
p=\frac{G-\sum_{i} T_{i}}{\sum_{j} w_{j} e_{i j}+\sum_{i \prime \neq i} \sum_{j} w_{j} e_{i^{\prime} j}} .
$$

When one university evaluates a growth strategy, it evaluates how its income changes according to:

$$
F_{i}=T_{i}+\frac{G-\sum_{i} T_{i}}{\sum_{i} w_{j} e_{i j}+\sum_{i \prime \neq i} w_{j} e_{i \prime j}}\left(\sum_{j} w_{j} e_{i j}\right)
$$

First statement of the proposition.

For any funding family $j$, the marginal funding $M R_{i}$ increases with total enrolment $e_{i j}$ :

$$
\frac{\partial M R_{i}}{\partial e_{i j}}=-w_{j} \frac{G-\sum_{i} T_{i}}{\left(\sum_{i} w_{j} e_{i j}+\sum_{i^{\prime} \neq i} w_{j} e_{i^{\prime} j}\right)^{2}}\left(\sum_{j} w_{j} e_{i j}\right)+\frac{G-\sum_{i} T_{i}}{\sum_{i} w_{j} e_{i j}+\sum_{i^{\prime} \neq i} w_{j} e_{i^{\prime} j}} w_{j}-c_{i j}
$$

This equation is positive if:

$$
p \underbrace{\left(1-\frac{\sum_{j} w_{j} e_{i j}}{\sum_{i} w_{j} e_{i j}+\sum_{i \neq i} w_{j} e_{i^{\prime} j}}\right)} w_{j}>c_{i j}
$$

Equilibrium adjustement on $\mathrm{p}$

Accordingly, universities have an interest in increasing enrolment when the (adjusted for equilibrium) weighted price is greater than the marginal costs.

Because the strategy space used therein is continuous, it implies the existence of a Nash equilibrium for any growth strategy. This reasoning holds for any set of programs $(j)$ and any number of universities (i), so the generality of the conclusion follows. 


\section{Second statement of the proposition.}

For any positive $p$ and set of weights $w$, a university that does not grow, while others do, necessarily faces a lower relative value of subsidy per student $(p / G)$. Hence, its total share of funding decreases.

Third statement of the proposition.

Globally, funding per student is given by:

$$
m=\frac{G}{\sum_{i j} e_{i j}}
$$

which implies:

$$
\frac{\delta m}{m}=\frac{\delta G}{G}-\frac{\sum_{i j} \delta e_{i j}}{\sum_{i j} e_{i j}} .
$$

That is, the growth rate of the funding per student declines if the growth rate of total subsidies is smaller than the growth rate of total enrolment.

\section{Proposition two:}

Without loss of generality, assume that programs $j$ and $j$ ' are such that $w_{j^{\prime}}>w_{j}$. Then, for any given level of substitution of enrolment $\Delta$, the marginal effect of funding is given by $\Delta\left(p w_{j^{\prime}}-p w_{j}-\left(c_{j^{\prime}}-c_{j}\right)\right)$. Accordingly, the marginal subsidy of university $i$ is given by the following equation:

$$
M S_{i}=T_{i}+\frac{G-\sum_{i} T_{i}}{\Delta\left(w_{j^{\prime}}-w_{j}\right)+\sum_{i} \sum_{j} w_{j} e_{i j}}\left(\Delta\left(w_{j^{\prime}}-w_{j}\right)+\sum_{j} w_{j} e_{i j}\right)-\Delta\left(c_{j^{\prime}}-c_{j}\right) .
$$

\section{First part of the proposition.}

The change in funding with respect to $\Delta$ is thus given by the following:

$$
\begin{aligned}
\frac{\partial M S_{i}}{\partial \Delta}= & -\left(w_{j^{\prime}}-w_{j}\right) \frac{G-\sum_{i} T_{i}}{\left(\Delta\left(w_{j^{\prime}}-w_{j}\right)+\sum_{i} \sum_{j} w_{j} e_{i j}\right)^{2}}\left(\Delta\left(w_{j^{\prime}}-w_{j}\right)+\sum_{j} w_{j} e_{i j}\right)+\cdots \\
& \ldots+\frac{G-\sum_{i} T_{i}}{\Delta\left(w_{j^{\prime}}-w_{j}\right)+\sum_{i} \sum_{j} w_{j} e_{i j}}\left(w_{j^{\prime}}-w_{j}\right)-\left(c_{j^{\prime}}-c_{j}\right)
\end{aligned}
$$

The is expression is positive if and only if:

$$
p \underbrace{\left(1-\frac{\left(\Delta\left(w_{j^{\prime}}-w_{j}\right)+\sum_{j} w_{j} e_{i j}\right)}{\left(\Delta\left(w_{j^{\prime}}-w_{j}\right)+\sum_{i} \sum_{j} w_{j} e_{i j}\right)}\right)}\left(w_{j^{\prime}}-w_{j}\right)>\left(c_{j^{\prime}}-c_{j}\right),
$$


which is the assumption of the proposition. Consequently, each university has an interest in substituting their enroled students towards higher weight programs.

Because the strategy space used therein is continuous, it implies the existence of a Nash equilibrium for any growth strategy. This reasoning holds for any set of programs $(j)$ and any number of universities (i), so the generality of the conclusion follows.

The two other parts of the proposition are shown in a similar fashion to that of Proposition 1. 


\section{Appendix 2. Additional Examples of Proposition 1 and 2}

Example 1: A two (identical) university system.

Each university has 100 enroled students. We further simplify by supposing that additional costs per enroled student are negligible $\left(c_{i j} \approx 0\right)$. The total appropriations is fixed to $G=100$ (100 percent), unconditional transfers towards universities $(T)$ is fixed to $10\left(T_{1}=T_{2}=10\right)$, and tuition fees are uniform at 0.1 (10\% of total funding). Institutions can either adopt a continuity strategy, or adopt a growth strategy where enrolment increases by $10 \%$. Because $G$ is fixed and costs are assumed negligible, this is a zero-sum game where both universities increase their enrollment. As such, Proposition 1 tells us that funding per student declines as the predicted outcome.

This example is summarized in Table 5 and the Nash equilibrium is shown in light blue.

Example 2: $A$ high tuition jurisdiction.

Let $i=1,2$ and assume 5 students enroled in each university $\left(e_{1}=e_{2}=5\right)$. Each university has a marginal cost $c_{1}=c_{2}$ $=1$. There is only one funding category $\left(w_{1}=1\right)$, tuition fees are set to ten $(f=10)$, the total public funding is set to $G=$ 50 , and unconditional transfers are set to ten $\left(T_{1}=T_{2}=10\right)$. The possible strategies are identical to the previous case ( $10 \%$ growth in enrolment if the growth is chosen). The analysis is provided in Table 6 below.

Insert Table 6 here

The Nash equilibrium is qualitatively like the one described in the main text. The impact on total funding per student is smaller because the proportion of tuition is higher. Nevertheless, because the growth in enrollment is higher than the growth of funds, funding declines.

Table 5. A simpler case with two identical universities

\begin{tabular}{|c|c|c|c|}
\hline & & Uni & \\
\hline & $\begin{array}{c}\left(S_{1}, S_{2}\right) \\
\left(\frac{F_{1}}{e_{1}}, \frac{F_{2}}{e_{2}}, \frac{G}{e_{1}+e_{2}}+f\right)\end{array}$ & Continuity & Growth \\
\hline 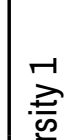 & Continuity Strategy & $\begin{array}{c}(60,60) \\
(0.6,0.6,0.6) \\
\end{array}$ & $\begin{array}{c}(58,62) \\
(0.58,0.57,0.576) \\
\end{array}$ \\
\hline 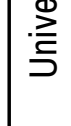 & Growth Strategy & $\begin{array}{c}(62,58) \\
(0.58,0.57,0.576)\end{array}$ & $\begin{array}{c}(61,61) \\
(0.55,0.55,0.55)\end{array}$ \\
\hline
\end{tabular}

Note: the Nash equilibrium is in light blue. Numbers are rounded, real calculations may differ up to a rounding error. 
Table 6. A high tuition jurisdiction

\begin{tabular}{|c|c|c|c|}
\hline & & \multicolumn{2}{|c|}{ University 2} \\
\hline & $\begin{array}{c}\left(N R_{1}, N R_{2}\right) \\
\left(S_{1}, S_{2}\right) \\
(p)\end{array}$ & Continuity & Growth \\
\hline \multirow{2}{*}{ 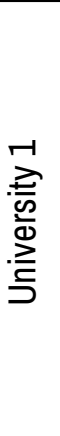 } & Continuity & $\begin{array}{c}(70.0,70.0) \\
(25.0,25.0) \\
(3.00)\end{array}$ & $\begin{array}{c}(69.3,75.2) \\
(24.3,25.7) \\
(2.85)\end{array}$ \\
\hline & Growth & $\begin{array}{c}75.2,69.3) \\
(25.7,24.3) \\
(2.87)\end{array}$ & $\begin{array}{c}(74.5,74.5) \\
(25.0,25.0) \\
(2.72)\end{array}$ \\
\hline
\end{tabular}

Note: the Nash equilibrium is in light blue. Numbers are rounded, real calculations may differ up to a rounding error. 


\section{Appendix 3. Conversion of Table CLARDER to CAFF}

Here is the list of conversions that required estimates from our part. The values in the third column are for 2014-2015. Insert Table of Appendix 3 here

\begin{tabular}{|c|c|c|}
\hline CAFF & CLARDER & TRANSFERRED FTES \\
\hline \multirow{4}{*}{$\begin{array}{l}3 \text { - Medicine, optometry and popula- } \\
\text { tion health }\end{array}$} & 03 - Optometry & ALL \\
\hline & 04 - Non-medical specialty in health & ALL \\
\hline & $\begin{array}{l}13-\text { Social sciences (for population } \\
\text { health) }\end{array}$ & $\begin{array}{l}\text { 1st cycle: } 1,406.9 \\
\text { 2nd cycle: } 539.5 \\
\text { 3rd cycle: } 179.3\end{array}$ \\
\hline & 23 - Medicine & ALL \\
\hline \multirow[t]{3}{*}{$\begin{array}{l}6 \text { - Rehabilitation, food science, } \\
\text { planning science and digital art }\end{array}$} & 04 - Non-medical specialty in health & $\begin{array}{l}\text { 1st cycle: } 2,203.5 \\
\text { 2nd cycle: } 1,241.6 \\
\text { 3rd cycle: } 99.8\end{array}$ \\
\hline & $\begin{array}{l}\text { 09-Architecture and environmental } \\
\text { design }\end{array}$ & ALL \\
\hline & $14-$ Geography & ALL \\
\hline 11 - Psychology & 13 - Social sciences & $\begin{array}{l}\text { 1st cycle: } 4,403.6 \\
\text { 2nd cycle: } 137.3 \\
\text { 3rd cycle: } 924.1\end{array}$ \\
\hline
\end{tabular}

Source: Québec Government (2016) and calculations. 


\section{Appendix 4. Complete Figures}
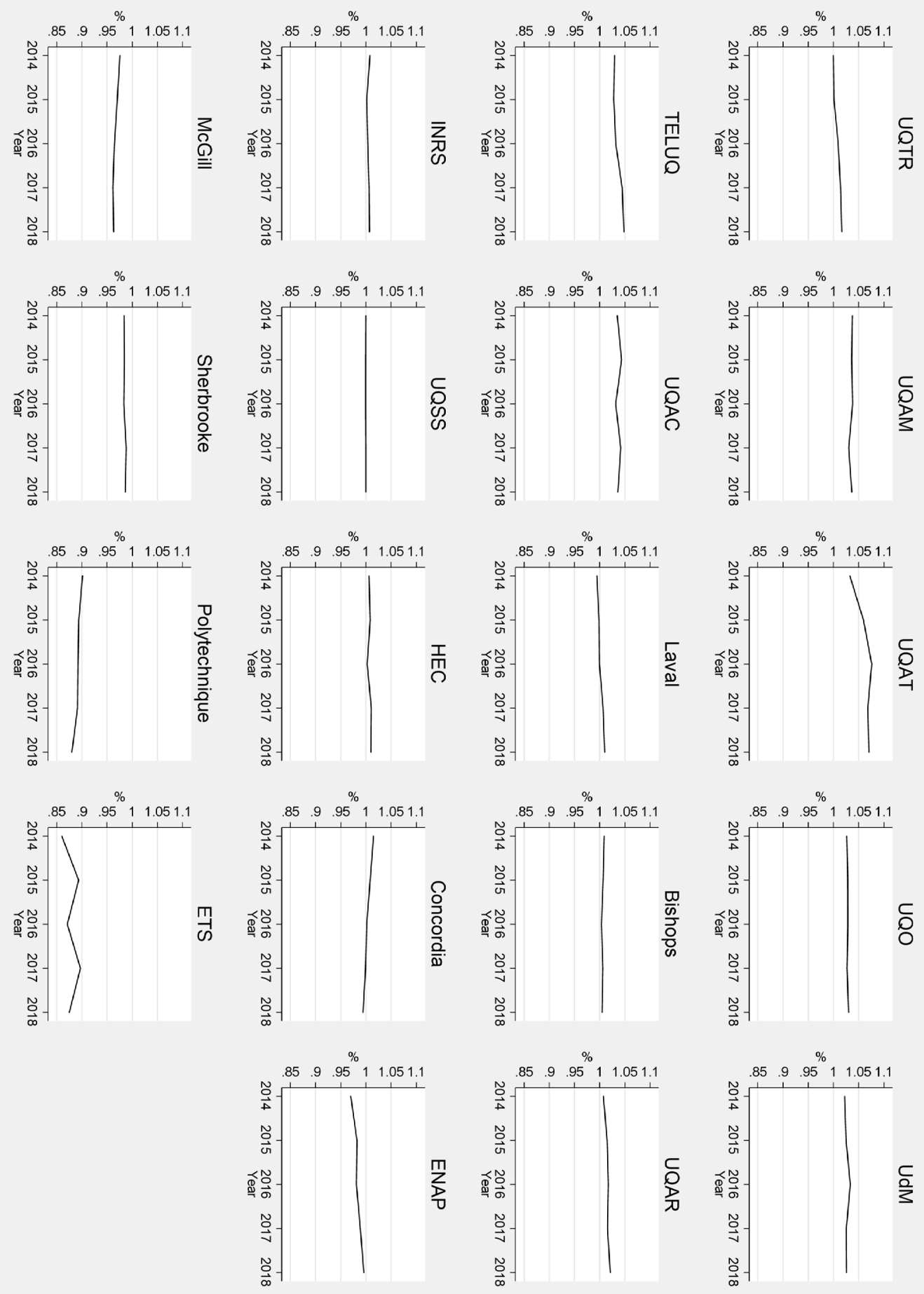

Figure 2 (extended) 

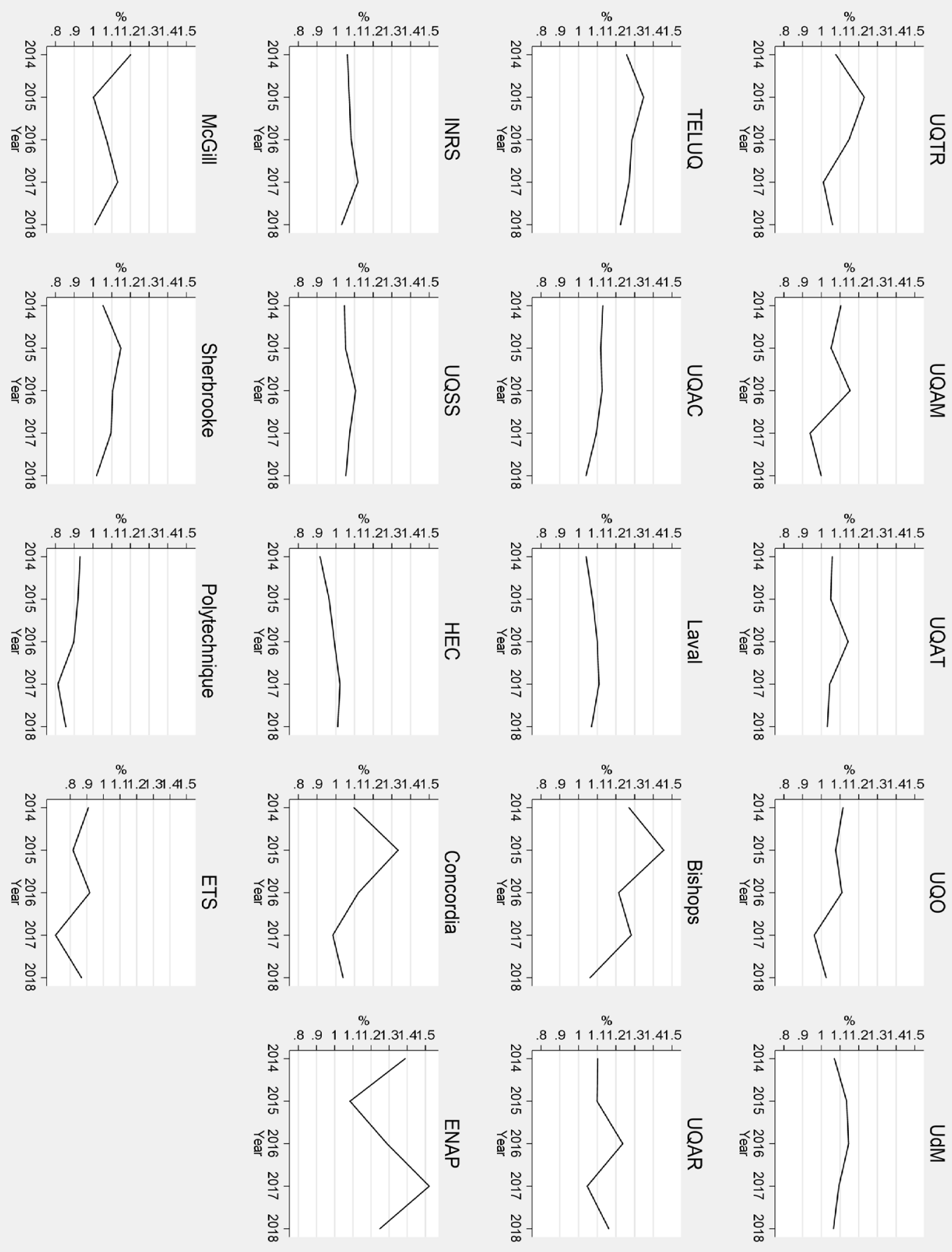

Figure 3 (extended) 

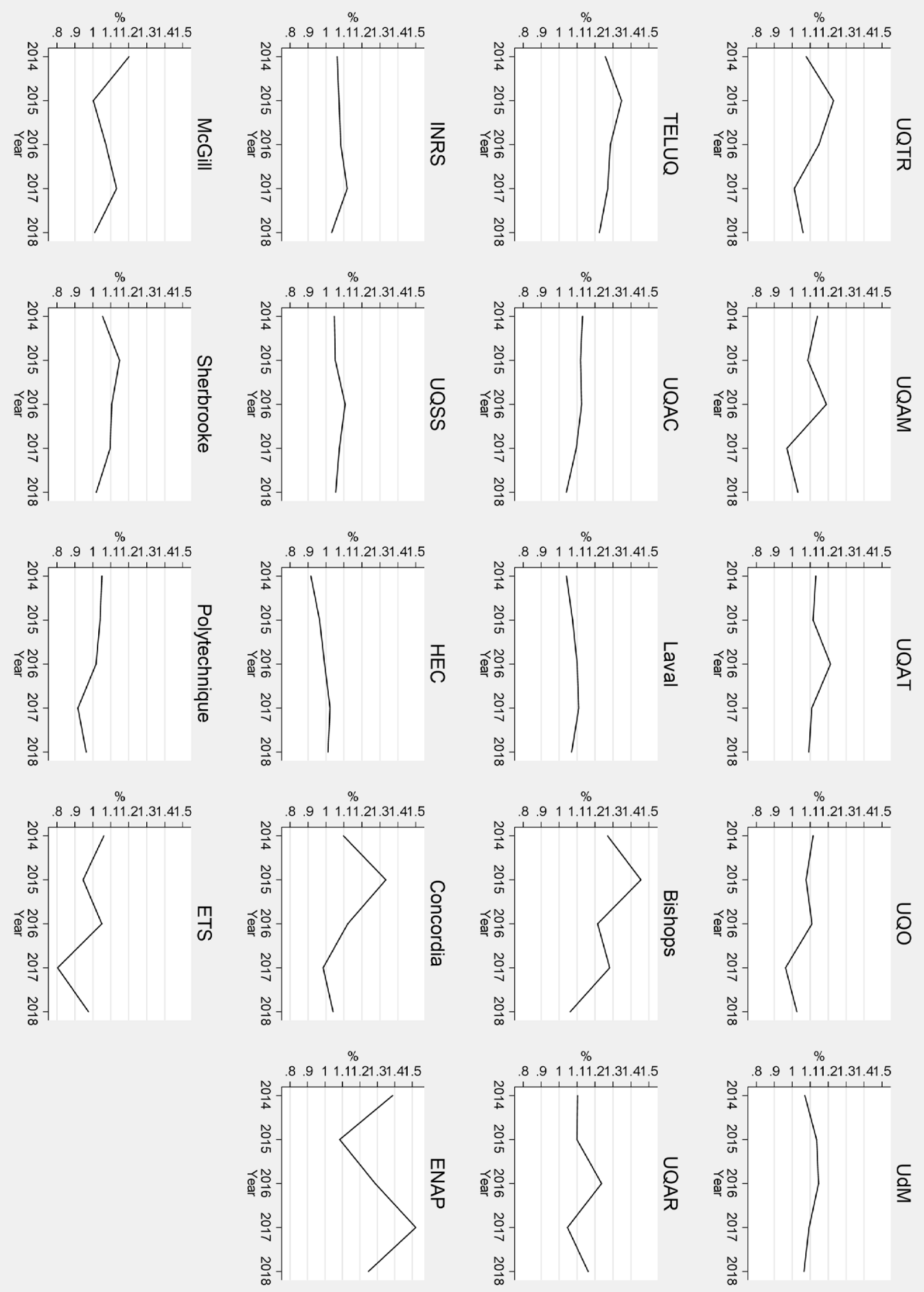

Figure 4 (extended) 

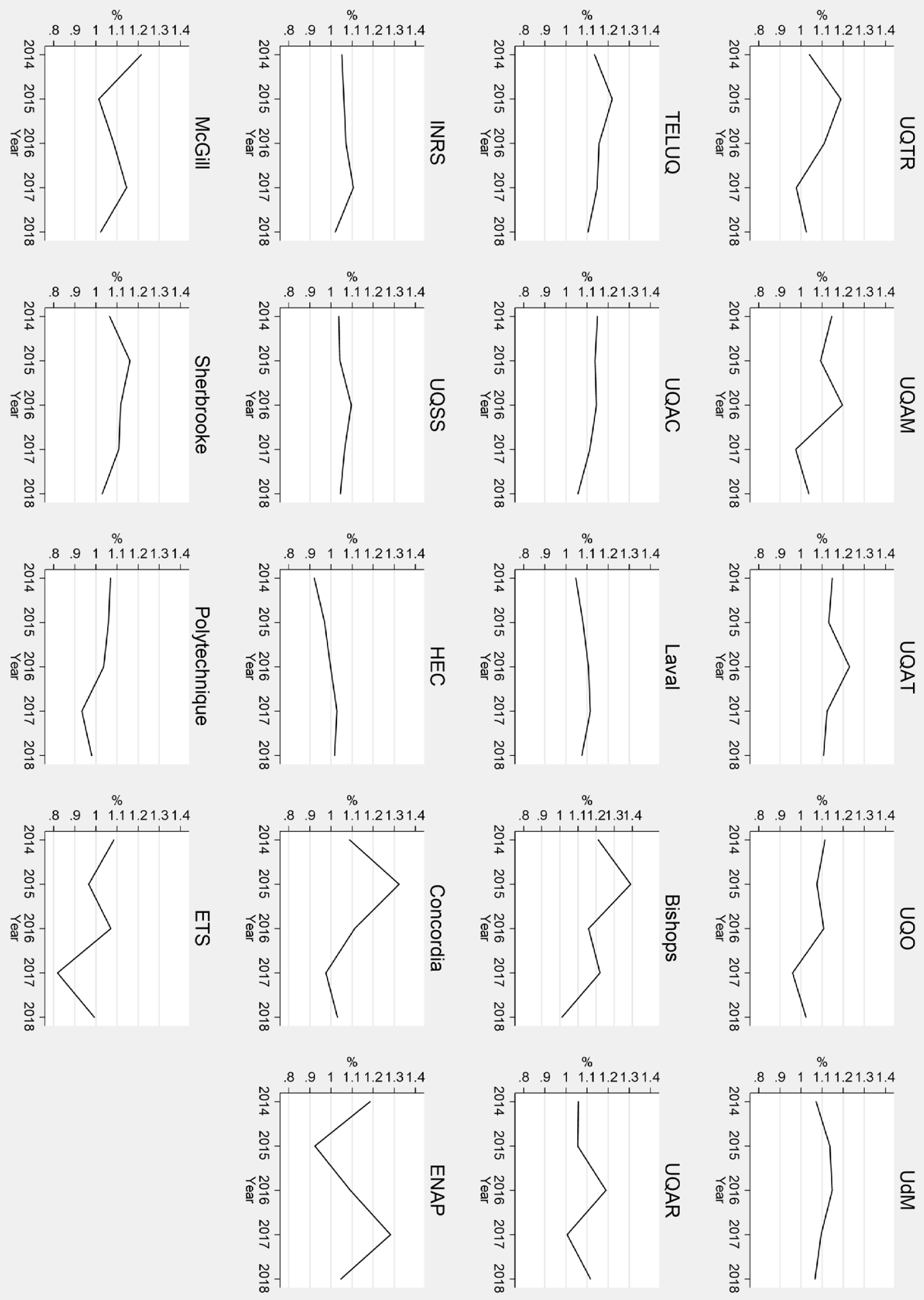

Figure 5 (extended) 